\title{
Presystolic Pulmonary Valve Opening in Constrictive Pericarditis
}

\author{
Chujiro Tanaka, M.D., Masaki Nishimoto, M.D., \\ Kazuhide Takeuchi, M.D., Kohtaro Fukukawa, M.D., \\ Seiki Kawai, M.D., Hisao OKu, M.D., and \\ Yoshiyasu Ikuno, M.D.
}

\section{SUMMARY}

Right heart pressure tracings were studied in 5 cases with constrictive pericarditis. The pressure of the A-wave in the right atrium of these cases was higher than the pulmonary arterial diastolic pressure. In addition, a presystolic wave appeared in the pulmonary arterial and the right ventricular pressure tracings, in coincidence with atrial systole. The pressure of this presystolic wave was similar to that of the right atrial A-wave. This suggests that the pulmonary valve opens following atrial systole, and then the blood flows into the pulmonary artery in the presystolic phase in patients with constrictive pericarditis.

In 2 of these cases, pulmonary valve echograms were recorded. The a-dip in these 2 cases was as deep as $8.4 \mathrm{~mm}$ and $9.6 \mathrm{~mm}(1.8-4.1 \mathrm{~mm}$ with a mean of $2.80 \mathrm{~mm}$ for normal men), and its duration was prolonged to $0.17 \mathrm{sec}$ and $0.18 \mathrm{sec}(0.10-0.13 \mathrm{sec}$ with a mean of $0.115 \mathrm{sec}$ for normal men). In conclusion, such a deep and prolonged a-dip on pulmonary valve echogram is presumably a sign of presystolic pulmonary valve opening.

\section{Additional Indexing Words:}

Echocardiogram a-dip Presystolic wave Isovolumetric contraction period

CONSTRICTIVE pericarditis is a chronic condition characterized by 1 dense thickening of pericardium which prevents proper diastolic filling of the ventricles. The characteristic clinical symptoms and hemodynamic changes of this disease are well known, but the pulmonary valve motion has not yet been investigated satisfactorily. The purpose of this report is to clarify the pulmonary valve motion in constrictive pericarditis. Japan.

From the First Department of Internal Medicine, Osaka City University Medical School, Osaka,

This paper was published in Japanese in Journal of Cardiography Vol. 7, No. 1, p. 55-61, 1977.

Address for reprint: Chujiro Tanaka, M.D., First Department of Internal Medicine, Osaka City University Medical School, 5-7, Asahimachi 1-chome, Abeno-ku, Osaka 545, Japan.

Received for publication December 5, 1978. 


\section{Materials AND Methods}

A total of 5 patients, 2 men and 3 women, with constrictive pericarditis confirmed by operation, were admitted to this study. Their ages ranged from 7 to 48 years, the mean being 28.8 years. All patients underwent right heart catheterization and pressure curves timed by expiration were recorded.

The pulmonary valve echograms seen in the cases with constrictive pericarditis were then compared with those of healthy people. Echocardiogram was taken at a speed of $50 \mathrm{~mm} / \mathrm{sec}$ by Aloka SSD-5B and a transducer of $2.25 \mathrm{MHz}$ with a diameter of $10 \mathrm{~mm}$ or Toshiba SSL $51 \mathrm{U}$ and a transducer of $2.0 \mathrm{MHz}$ with a diameter of $10 \mathrm{~mm}$. Respiration was timed by expiration. All cases were examined in a recumbent position with the transducer placed in the second or third intercostal space along the left sternal border. The pulmonary valve echograms were identified by rotating the transducer ventrally, leftward and cephalad from the position of the aortic valve leaflets.

Pulmonary valve echograms were successfully recorded in 2 of the 5 cases with constrictive pericarditis. The depth and duration of the a-dip were determined, and the results were compared with those of 10 healthy people.

As shown in Fig. 1, the depth of the a-dip was defined as the amplitide of the a-dip from the point $f$, and the duration as the time needed for the a-dip to return to the first changing point on the baseline from the point $f{ }^{1)}$ The mean value of 5 heart beats was calculated.
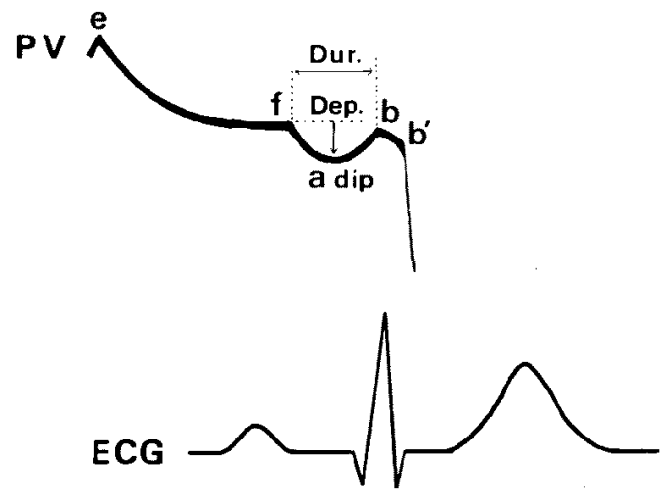

Fig. 1. Illustration of normal pulmonary valve echogram. Dur=duration of the a-dip; Dep=depth of the a-dip.

\section{Results}

The right heart catheterization data of the 5 cases with constrictive pericarditis are shown in the Table. It was shown that A-wave pressure of the right atrium was higher than the right ventricular end-diastolic pressure and diastolic pulmonary arterial pressure. Systolic pulmonary arterial pressure measured $40 \mathrm{mmHg}$ or less in all of these patients, and thus, no cases 
Table I. Cardiac Catheterization Data

\begin{tabular}{|c|c|c|c|c|c|c|c|c|c|c|c|}
\hline \multirow{3}{*}{ Case } & \multirow{3}{*}{ Age } & \multirow{3}{*}{ Sex } & \multicolumn{9}{|c|}{ Pressure $(\mathrm{mmHg})$} \\
\hline & & & \multicolumn{3}{|c|}{ MPA } & \multicolumn{3}{|c|}{ RV } & \multicolumn{3}{|c|}{ RA } \\
\hline & & & Syst. & Diast. & PS & Syst. & Diast. & PS & a & $v$ & $\overline{\mathrm{m}}$ \\
\hline 1 & 7 & $\mathbf{M}$ & 35 & 24 & 26 & 38 & 24 & 26 & 26 & 22 & 20 \\
\hline 2 & 19 & $\mathrm{~F}$ & 32 & 20 & 25 & 34 & 24 & 25 & 25 & 23 & 20 \\
\hline 3 & 34 & $\mathrm{~F}$ & 24 & 8 & 11 & 27 & 12 & 11 & 12 & 10 & 9 \\
\hline 4 & 35 & F & 23 & 10 & 14 & 25 & 9 & 13 & 13 & 10 & 9.5 \\
\hline 5 & 49 & $\mathbf{M}$ & 22.5 & 6 & 10.5 & 24 & 8.5 & 12 & 9.5 & 7.5 & 5 \\
\hline
\end{tabular}

$\mathrm{MPA}=$ main pulmonary artery ; $\mathrm{RV}=$ right ventricle ; $\mathrm{RA}=$ right atrium ; Syst. $=$ systolic pressure; Diast. $=$ diastolic pressure; $P S=$ presystolic wave pressure; $a=a$ wave pressure $; \quad v=v$ wave pressure; $\overline{\mathrm{m}}=$ mean pressure.

had marked pulmonary hypertension.

The following features were seen in the intracardiac pressure tracings of all patients: i.e. The right atrial pressure tracing showed W-pattern. A dipand-plateau pattern in the diastolic phase and an abnormal positive presystolic wave were observed in the right ventricular pressure tracing. This was coincident with the right atrial contarction. A similar presystolic wave

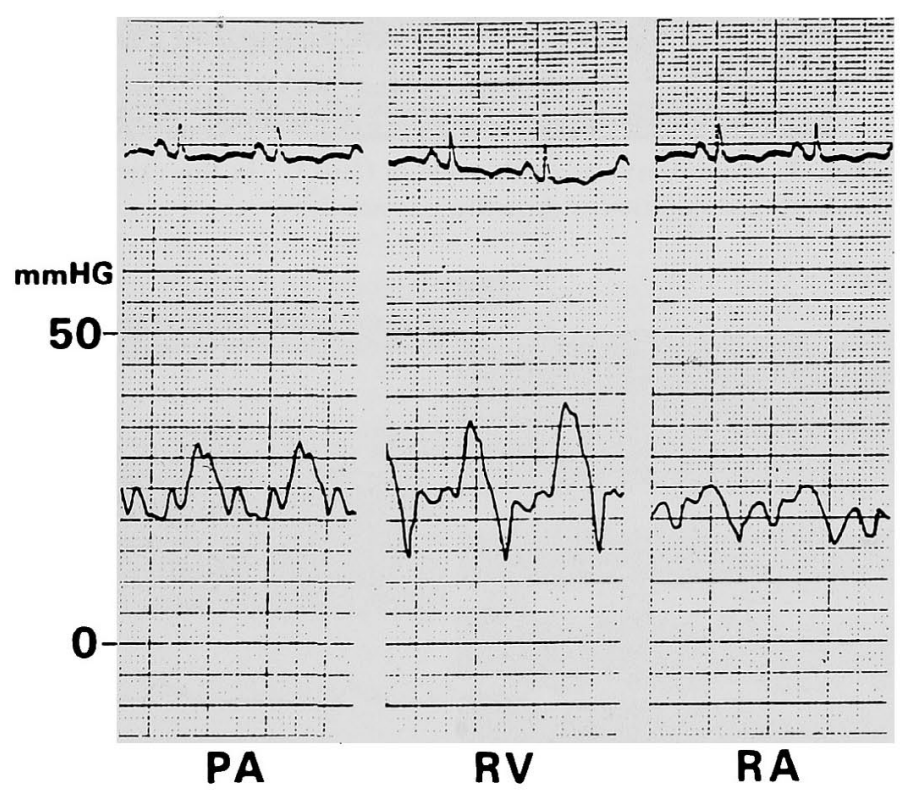

Fig. 2. Pressure tracings from the right atrium (RA), right ventricle $(\mathrm{RV})$, and main pulmonary artery (PA). Note the prominent presystolic wave in the right ventricular and main pulmonary arterial tracings. The atrial $\mathrm{A}$-wave is equal in height to the presystolic wave in the right ventricle and pulmonary artery. 
was also seen in the pulmonary arterial pressure tracing. The pressure of this presystolic wave in the pulmonary arterial pressure tracing was almost the same as that of the presystolic wave in the right ventricle and that of the A-wave in the right atrial pressure tracing (Fig. 2).

The a-dips in the pulmonary valve echograms were also studied. The depth of the a-dips in 10 healthy people ranged from 1.8 to $4.1 \mathrm{~mm}$ with a mean value of $2.80 \mathrm{~mm}$, and its duration 0.10 to $0.13 \mathrm{sec}$ with a mean value of $0.115 \mathrm{sec}$. The depth of the a-dip in Case 1 was $8.4 \mathrm{~mm}$, and its duration

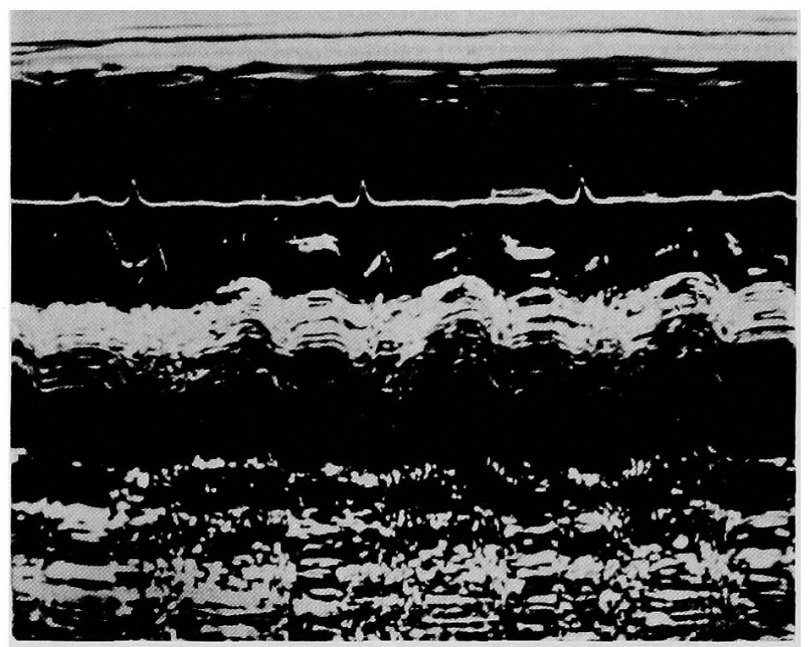

Fig. 3. Pulmonary valve echogram in Case 1 . In this case an increase in the depth and duration of the a-dip was noted.

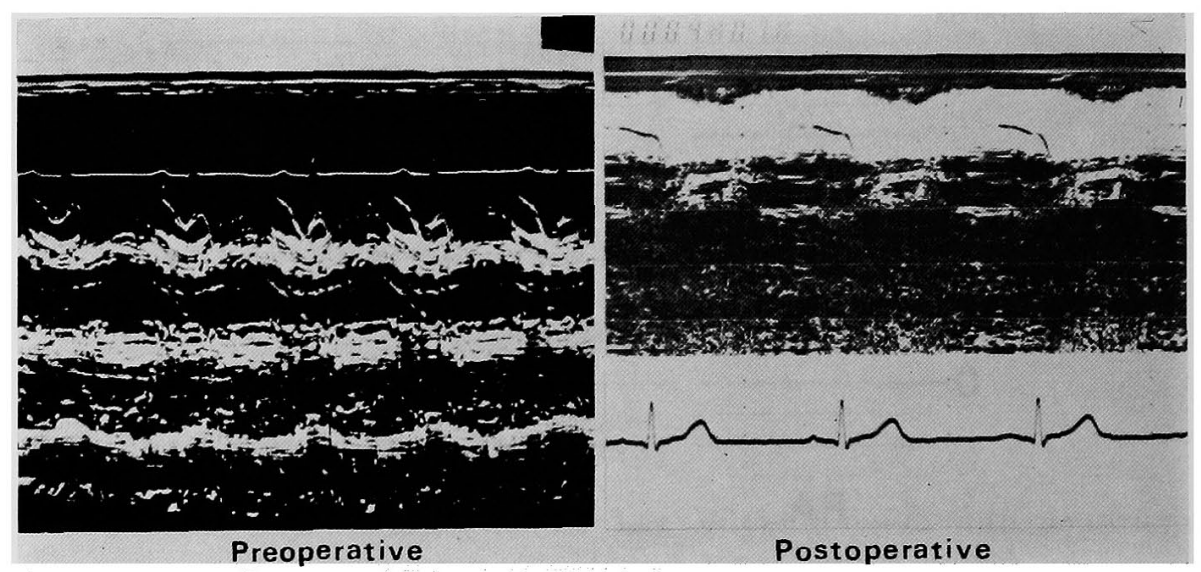

Fig. 4. Pulmonary valve echograms in Case 2 before (left) and after (right) the operation. Before the operation, an increase in the depth and duration of the a-dip was noted. After the operation, the depth and duration were in the normal ranges. 
was prolonged to $0.17 \mathrm{sec}$. The point $b$, which is both the end point of the a-dip and the starting point of the sytolic opening phase of pulmonary valve, takes the form of a sharp turning point, and the point $b^{\prime}$, which often occurs immediately after the point $b$ on pulmonary valve echogram, is not observed (Fig. 3).

In Case 2, the pulmonary valve echograms were successfully recorded both before and after operation. The preoperative a-dip depth was as deep as $9.6 \mathrm{~mm}$, and its duration was prolonged to $0.18 \mathrm{sec}$. In the post-operative condition, where the hemodynamics of the patient were considered as returning to normal ranges, the depth of the a-dip was reduced to $1.8 \mathrm{~mm}$, and its duration was also reduced to $0.12 \mathrm{sec}$, both values returning to normal ranges (Fig. 4). The depth of the a-dips of these two patients is compared with that of healthy people in Fig. 5 and the duration in Fig. 6.

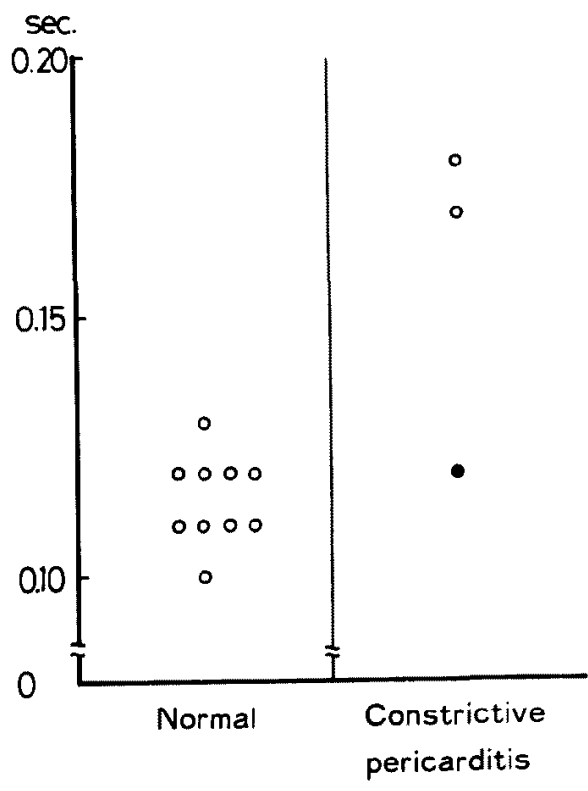

Fig. 5

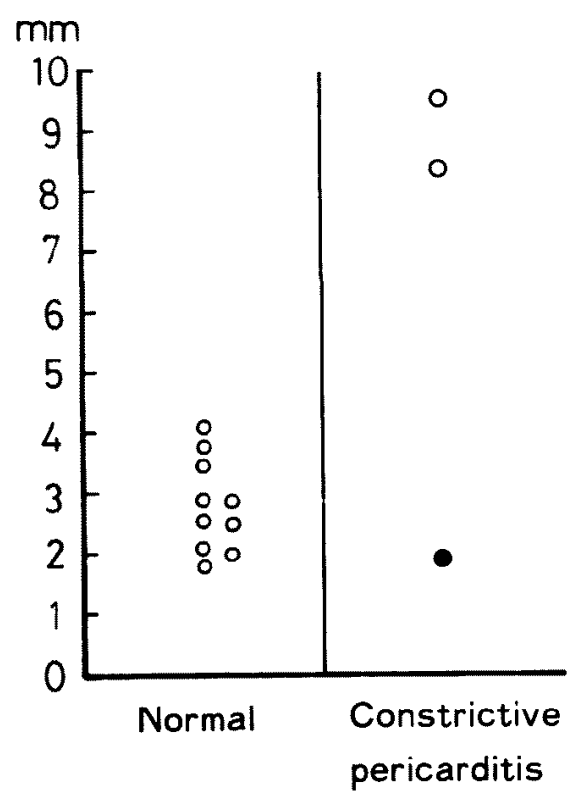

Fig. 6

Fig. 5 (left). The dcpth of the a-dip. In constrictive pericarditis, the depth of the a-dip was increased.

= Postoperative value of Case 2.

Fig. 6 (right). The duration of the a-dip. In constrictive pericarditis, the duration of the a-dip was prolonged. $\quad=$ Postoperative value of Case 2 .

\section{Discussion}

Reports regarding opening of the pulmonary valve and blood flow from the right ventricle to the pulmonary artery in the diastolic phase have not appeared frequently., ${ }^{2-9)}$ Reeve et $\mathrm{al}^{2)}$ and Hultgren et $\mathrm{al}^{3 \text { ) }}$ recorded both 
pulmonary arterial and right ventricular pressure tracings simultaneously in patients with pulmonary stenosis, and demonstrated that right ventricular end-diastolic pressure were occasionally higher than pulmonary diastolic pressure, and that when such changes were observed, the pulmonary valve was dome-shaped or was opened. Somer et $\mathrm{al}^{4 /}$ and Guimaraes et $\mathrm{al}^{5)}$ found that a positive presystolic wave, which was coincident with the A-wave of the right atrium both in timing and pressure values, was seen in the pulmonary arterial pressure curve in patients with endomyocardial fibrosis, and thus, they suggested that diastolic pulmonary flow might exist in such conditions. Similar findings have also been reported in Ebstein's anomaly ${ }^{6)}$ and Uhl's anomaly. ${ }^{31,8)}$ Wolfson et al, ${ }^{9}$ ' who carried out cineangiography in carcinoid heart, observed that contrast media flowed from the right atrium to the pulmonary artery via the right ventricle during the diastolic phase.

In the 5 cases with constrictive pericarditis studied in this trial, pulmonary arterial systolic pressure was normal or slightly raised, and the right atrial A-wave exceeded pulmonary arterial diastolic pressure. In addition, a presystolic wave appeared in the pulmonary arterial pressure tracing coincident with right atrial contraction. The pressure of this presystolic wave was similar to those of the presystolic wave in the right ventricle and the right atrial A-wave. This suggests that the pulmonary valve also opens during the right atrial systole, and thus, presystolic flows from the right ventricle to the pulmonary artery in constrictive pericarditis.

The normal pulmonary valve echogram may have a small a-dip in diastole coinciding with atrial contraction. The depth of the a-dip was 1.8 to $4.1 \mathrm{~mm}$ for healthy people, with a mean value of $2.80 \mathrm{~mm}$, but this was apparently increased to $8.4 \mathrm{~mm}$ and $9.6 \mathrm{~mm}$ in Cases 1 and 2 respectively. Likewise, the duration of the a-dip was 0.1 to $0.13 \mathrm{sec}$ for healthy people, and this was clearly prolonged to $0.17 \mathrm{sec}$ in Case 1 and to $0.18 \mathrm{sec}$ in Case 2 . In Case 2, both the depth and duration of the a-dip were restored to normal ranges after operation. Accordingly, the deep and prolonged a-dip may be regarded as an indicator of presystolic pulmonary valve opening, when the phenomena of the intracardiac pressure curve are also taken into account. It has been believed that a deep a-dip on pulmonary valve echogram is a sign of presystolic pulmonary valve opening or doming. ${ }^{8,10), 11,}$ However, in our 2 cases with constrictive pericarditis, the a-dip was not only deep but also prolonged. A-dips seen in healthy people are presumably produced by mild doming of the pulmonary valve following atrial contraction. In our 2 cases with constrictive pericarditis, however, the deep a-dip seemed to be associated with the opening of the pulmonary valve during the presystolic period, when the intracardiac pressure tracing taken into consideration. The prolonged 
duration of the a-dip in our 2 cases can be explained as follows.

The intracardiac pressure tracings show that the right ventricular ejection appears when the presystolic wave pressure and the subsequent enddiastolic pressure in the right ventricle become higher than the pulmonary diastolic pressure. Accordingly, the isovolumetric contraction period does not exist in the right ventricle. In this condition, therefore, the end point of the a-dip on pulmonary valve echogram, that is, the point $b$, is simultaneously the starting point of the ejection period of the right ventricle. In other words, the right ventricular isovolumetric contraction period, which should be independently present, is contained in the a-dip, and thus, the duration of the a-dip is prolonged. These phenomena are suggestive of existence of the presystolic pulmonary valve opening.

\section{References}

1. Gramiak R, Nanda NC, Shah PM: Echocardiographic detection of the pulmonary valve. Radiology 102: 153, 1972

2. Reeve R: Variations of the ejection click in valvular pulmonic stenosis. Clin Res 14: 129, 1966

3. Hultgren HN, Reeve R, Cohn K, McLeod R: The ejection click of valvular pulmonic stenosis. Girculation 40:631, 1969

4. Somers K, Brenton DP, D'Arbela PG, Fowler JM, Kanyerezi BR, Sood NK: Haemodynamic features of severe end-myocardial fibrosis of right ventricle, including comparison with constrictive pericarditis. Brit Heart J 30: 322, 1968

5. Guimaraes AC, Filho AS, Esteves JP, Vinhaes LSA, Abreu WN: Hemodynamics in endomyocardial fibrosis. Am Heart J 88: 294, 1974

6. Genton E, Blount SG Jr: The spectrum of Ebstein's anomaly. Am Heart J 73: 395, 1967

7. Gasul BM, Arcilla RA, Lev M: Heart Disease in Children; Diagnosis and Treatment. Philadelphia, Lippincott, p 751, 1966

8. French JW, Baum D, Popp RL: Echocardiographic findings in Uhl's anomaly. Demonstration of diastolic pulmonary valve opening. Am J Cardiol 36: 349, 1975

9. Wolfson PM, Basta LL, Snodgrass RP, Kioschos JM: Diastolic blood flow into the pulmonary artery in carcinoid heart disease. Am J Cardiol 36: 21, 1975

10. Weyman AE, Dillon JC, Feigenbaum H, Chang S: Echocardiographic differentiation of infundibular from valvular pulmonary stenosis. Am J Cardiol 36: 21, 1975

11. Weyman AE, Dillon JC, Feigenbaum $\mathrm{H}$, Chang $\mathrm{S}$ : Echocardiographic patterns of pulmonary valve motion in valvular pulmonary stenosis. Am J Cardiol 34: 644, 1974 